\title{
GMR
}

\section{Genetic analysis of floral organ size in broccoli $\times$ cabbage via a mixed inheritance model of a major gene plus polygene}

\author{
J.S. Shu, Y.M. Liu, Z.S. Li, L.L. Zhang, Z.Y. Fang, L.M. Yang, M. Zhuang, \\ Y.Y. Zhang and H.H. Lv \\ Key Laboratory of Biology and Genetic Improvement of Horticultural Crops, \\ Institute of Vegetables and Flowers, Chinese Academy of Agricultural Sciences, \\ Ministry of Agriculture, Beijing, China \\ Corresponding author: Y.M. Liu \\ E-mail: liuyumeicaas@126.com
}

Genet. Mol. Res. 15 (2): gmr.15027554

Received August 8, 2015

Accepted December 3, 2015

Published April 7, 2016

DOI http://dx.doi.org/10.4238/gmr.15027554

ABSTRACT. Broccoli and cabbage are important vegetable crops that produce hybrid seeds after insect pollination; the size of floral organs is crucial for this process. To investigate the genetic characteristics of floral organ sizes (corolla width, petal length and width, and lengths of stamen, anther, style, and stigma) and to improve the flower size and breeding efficiency of broccoli, we used multi-generation analysis of a major gene plus polygene model. Six populations obtained from a broccoli inbred line 93219 (small floral organs) and cabbage inbred line 195 (large floral organs) were used for the analysis. Corolla and petal width and stamen and anther length were controlled by the additive-dominanceepistasis polygene model. The heritability of these traits in $\mathrm{BC}_{1}, \mathrm{BC}_{2}$, and $\mathrm{F}_{2}$ generations was high (72.80-93.76\%). Petal and stigma length were governed by the two major genes of additive-dominance-epistasis effects plus additive-dominance polygene model; the major gene heritability in the $F_{2}$ generation were 79.17 and $65.77 \%$, respectively. Style length was controlled by one major gene of additive-dominance effects plus additive- 
dominance-epistasis polygene model; the major gene heritability in $\mathrm{BC}_{1}$, $\mathrm{BC}_{2}$, and $\mathrm{F}_{2}$ were $40.60,10.35$, and $38.44 \%$, respectively; the polygene heritability varied from 41.85 to $68.44 \%$. Our results provide important genetic information for breeding, which could guide improvement of flowerrelated traits and lay the foundation for quantitative trait loci mapping of the flower-size traits in Brassica.

Key words: Broccoli; Floral organ; Polygene; Genetic analysis

\section{INTRODUCTION}

Flowers are vital reproductive organs. They are also crucial for plants in attracting pollinators, which play an irreplaceable role in species evolution and agricultural production. Flower size is generally considered the most important factor for pollinators and is often correlated with other traits that increase the pollinator visitation rates (Fenster et al., 2006). Large floral organ display is associated with a higher capability to attract pollinators (Young and Stanton, 1990; Kudoh and Wigham, 1998; Thompson, 2001; Nattero et al., 2010). Flowers with large perianths often attract more pollinators, partly because of the higher nectar rewards, and the petal size is positive correlated with this behavior (Molina-Montenegro and Cavieres, 2006). Therefore, pollinators tend to visit larger flowers rather than the smaller ones both in the same and between different plant species. Meanwhile, the behavior of the pollinator can also increase the directional selection, favoring large flowers in plant evolution (Harder and Johnson, 2009; Dudash et al., 2011). Moreover, flower size also affects the fruiting characteristics of plants; the fruit set of larger flowers was observed to be significantly higher than that of smaller ones, in fruit trees (Johnson et al., 2011; Wetzstein et al., 2013). The relative position of anthers and stigmas can also influence pollination and the fruit set (Conner and Sterling, 1995; Rodrigo and Herrerro, 2002; Ruiz and Egea, 2008).

Broccoli (Brassica oleracea L. var. italica) and cabbage (Brassica oleracea L. var. capitata) are important vegetables, especially broccoli, which is the most commercial form of Brassica vegetable (Walley et al., 2012). Driven by its reported richness in nutrients and health benefits, broccoli production and consumption have risen notably recently (Van Poppel et al., 1999; Finley, 2003; Jeffery and Araya, 2009). The demand for its seeds has increased sharply in recent years. However, the hybrid production of broccoli is difficult and produces low yields in conventional breeding; therefore, breeders urgently need to improve the yield of hybrids. Small flower size is one of the main internal restricting factors that affect pollination and hybrid seed yield in broccoli. If other traits of broccoli plant remained unchanged or similar, the ability to attract pollinators and hybrid seed yield would markedly change by increasing the flower size (Shu et al., 2014, 2015). Thus, it is feasible to increase the broccoli hybrid seed yield by improving the flower size. For this, clarifying the genetic rules governing floral organ sizes is essential. Due to lack of large flower sizes in broccoli and flower sizes of cabbage being usually larger, the hybrid progenies are easy to obtain using a cabbage by broccoli cross. Therefore, in the present study, we investigated the major gene plus polygene genetic basis of broccoli $x$ cabbage flower organ size using six populations $\left(P_{1}\right.$, $\mathrm{P}_{2}, \mathrm{~F}_{1}, \mathrm{BC}_{1}, \mathrm{BC}_{2}$, and $\mathrm{F}_{2}$ ) derived from crosses of broccoli and cabbage, with a view to providing genetic information for breeders who wish to use flower size to improve the broccoli pollination efficiency and seed yield. 


\section{MATERIAL AND METHODS}

\section{Parent materials and population construction}

To study the inheritance of flower size, large flower size $P_{1}$ (cabbage inbred line 195; flowering does not need vernalization) and small flower size $P_{2}$ (broccoli inbred line 93219), both bred by the Institute of Vegetables and Flowers, Chinese Academy of Agricultural Sciences, were used for the cross and construction of segregation populations. From the spring of 2013 to the winter of 2014, the two parent materials were crossed and the floral organ sizes of the $F_{1}$ hybrids were evaluated in the following spring and winter, four consecutive times. The results were similar: the flower sizes (nine traits) were significantly different between the two parents and those of the orthogonal and reciprocal crosses of the $F_{1}$ hybrids had no differences and all ranged between the two parents.

In the spring of 2013, $P_{1}$ and $P_{2}$ were planted in the cold frame; $F_{1}$ was configured by $P_{2}$ $x P_{1}$. In the winter of 2013, $P_{1}, P_{2}$, and $F_{1}$ were all planted in the greenhouse, and the seeds of six populations were obtained: $P_{1}, P_{2}, F_{1}, B C_{1}\left[\left(P_{2} \times P_{1}\right) \times P_{1}\right], B C_{2}\left[\left(P_{2} \times P_{1}\right) \times P_{2}\right]$, and $F_{2}\left[\left(P_{2} \times P_{1}\right) \times\right.$ $\left.\left(P_{2} \times P_{1}\right)\right]$ through selfing and backcrossing, respectively. These experiments were carried out in the experimental field (Haidian, Beijing, China) of the Institute of Vegetables and Flowers, China Agricultural Academy of Science, under standard field conditions.

\section{Field experiments and measurement of the floral organ sizes}

In the summer of 2014 , all the six populations $\left(\mathrm{P}_{1}, \mathrm{P}_{2}, \mathrm{~F}_{1}, \mathrm{BC}_{1}, \mathrm{BC}_{2}\right.$, and $\left.\mathrm{F}_{2}\right)$ were planted (row spacing of $0.35 \mathrm{~m}$ and plant spacing of $0.3 \mathrm{~m}$ ) in a greenhouse of the Nankou (Changping, Beijing, China) experimental farm, Institute of Vegetables and Flowers, China Agricultural Academy of Science. Eight flower-size-related traits (corolla width, petal length and width, and the lengths of long and short stamens, anther, style, and stigma) were measured with digital Vernier calipers. For each plant, measurements were taken two to three times (10-20 flowers) for 15-30 days, after the first day of complete opening of flowers during the full-flowering period in the winter of 2014 . For $\mathrm{P}_{1}, \mathrm{P}_{2}, \mathrm{~F}_{1}, \mathrm{BC}_{1}, \mathrm{BC}_{2}$, and $\mathrm{F}_{2}$, there were $45,46,46,187,192$, and 428 plants, respectively. All the experiments were performed under normal management, e.g., timely watering and fertilization.

\section{Statistical analysis}

The data were analyzed with Excel 2007 and SAS 9.2 softwares. For the six populations $\left(P_{1}, P_{2}, F_{1}, B C_{1}, B C_{2}\right.$, and $\left.F_{2}\right)$, joint segregation analysis of the mixed genetic model of major gene plus polygene (Zhang and Gai, 2000; Zhang et al., 2003; Gai et al., 2003) was used to investigate the genetic basis of floral organ sizes. Twenty-four related genetic models were categorized into five types: the A model (inheritance controlled by one pair of major gene), B model (inheritance controlled by two pairs of major genes), C model (inheritance controlled by polygenes), D model (inheritance controlled by one pair of major gene plus polygenes), and the $\mathrm{E}$ model (inheritance controlled by two pairs of major genes plus polygenes). Each generation and component of the related distribution parameters were estimated by the maximum likelihood and the iterated expectation and conditional maximization (IECM) algorithm. The most appropriate genetic model was selected according to Akaike's information criterion (AIC) values (the least or relatively lower AIC value) for the candidate models (Akaike, 1977). Further, the most appropriate-fitting model was defined by five statistical parameters $\left(U_{1}{ }^{2}, U_{2}{ }^{2}, U_{3}{ }^{2},{ }_{n} W^{2}\right.$, and $\left.D_{n}\right)$. Finally, the least squares 
estimation method was used to determine the gene effects and genetic variances of the most appropriate genetic model. The genetic variances of the major gene $\left(\sigma^{2}{ }_{\mathrm{mg}}\right)$ and polygene $\left(\sigma_{\mathrm{pg}}^{2}\right)$ and the heritability of the major gene $\left(h^{2}{ }_{\mathrm{mg}}\right)$ and polygene $\left(h_{\mathrm{pg}}{ }\right)$ were calculated according to the equations $\left(\sigma_{p}^{2}\right.$ : phenotypic variance of population, $\sigma_{\mathrm{e}}^{2}$ : error variance).

$$
\begin{gathered}
\sigma_{\mathrm{mg}}^{2}=\sigma_{\mathrm{p}}^{2}-\sigma_{\mathrm{e}}^{2}-\sigma_{\mathrm{pg}}^{2} \\
\sigma_{\mathrm{pg}}^{2}=\sigma_{\mathrm{p}}^{2}-\sigma_{\mathrm{mg}}^{2}-\sigma_{\mathrm{e}}^{2} \\
h_{\mathrm{mg}}^{2}=\sigma_{\mathrm{mg}}^{2} / \sigma_{\mathrm{p}}^{2} \times 100 \% \\
h_{\mathrm{pg}}^{2}=\sigma_{\mathrm{pg}}^{2} / \sigma_{\mathrm{p}}^{2} \times 100 \%
\end{gathered}
$$

\section{RESULTS}

\section{Phenotypic data analysis}

The eight flower-size-related traits including corolla width, petal length and width, length of long and short stamens, anther, style, and stigma were significantly different $(P<0.05)$ among the $\mathrm{P}_{1}, \mathrm{P}_{2}$, and $\mathrm{F}_{1}$ hybrids. The traits of the $\mathrm{F}_{1}$ hybrid were located between the values of the two parents and were mostly closer to $\mathrm{P}_{1}$ (Table 1 ).

Table 1. Statistics of traits related to floral organ sizes of the $P_{1}, P_{2}$, and $F_{1}$ populations in the winter of 2014.

\begin{tabular}{l|c|c|c}
\hline Trait & $\mathrm{P}_{1}(\mathrm{~mm})$ & $\mathrm{P}_{2}(\mathrm{~mm})$ & $\mathrm{F}_{1}(\mathrm{~mm})$ \\
\hline Corolla width & $26.20 \pm 1.33^{\mathrm{a}}$ & $16.52 \pm 0.48^{\mathrm{c}}$ & $21.83 \pm 1.03^{\mathrm{b}}$ \\
\hline Petal length & $22.30 \pm 0.68^{\mathrm{a}}$ & $14.35 \pm 0.46^{\mathrm{c}}$ & $18.54 \pm 0.85^{\mathrm{b}}$ \\
\hline Petal width & $9.67 \pm 0.49^{\mathrm{a}}$ & $6.15 \pm 0.28^{\mathrm{c}}$ & $8.01 \pm 0.56^{\mathrm{b}}$ \\
\hline Long stamen length & $14.99 \pm 0.43^{\mathrm{a}}$ & $9.17 \pm 0.42^{\mathrm{c}}$ & $12.88 \pm 0.38^{\mathrm{b}}$ \\
\hline Short stamen length & $13.61 \pm 0.50^{\mathrm{a}}$ & $8.01 \pm 0.39^{\mathrm{c}}$ & $11.41 \pm 0.33^{\mathrm{b}}$ \\
\hline Anther length & $4.63 \pm 0.21^{\mathrm{a}}$ & $2.13 \pm 0.11^{\mathrm{c}}$ & $3.54 \pm 0.14^{\mathrm{b}}$ \\
\hline Style length & $10.67 \pm 0.53^{\mathrm{a}}$ & $6.86 \pm 0.49^{\mathrm{c}}$ & $8.79 \pm 0.61^{\mathrm{b}}$ \\
\hline Stigma length & $3.47 \pm 0.29^{\mathrm{a}}$ & $1.39 \pm 0.23^{\mathrm{c}}$ & $2.32 \pm 0.25^{\mathrm{b}}$ \\
\hline
\end{tabular}

Values followed by different letters are significantly different at 0.05 probability level.

The ranges and coefficients of variation (CV\%) of the flower-size-related traits among the six populations $\left(\mathrm{P}_{1}, \mathrm{P}_{2}, \mathrm{~F}_{1}, \mathrm{BC}_{1}, \mathrm{BC}_{2}\right.$, and $\left.\mathrm{F}_{2}\right)$ were analyzed statistically and are presented in Table 2. The ranges and $C V \%$ among the $\mathrm{BC}_{1}, \mathrm{BC}_{2}$, and $\mathrm{F}_{2}$ generations were higher than those of the $P_{1}, P_{2}$, and $F_{1}$ (Table 2), indicating the existence of real variations in heredity and more genetic polymorphisms in the three segregating populations, which provided a good foundation for genetic analysis. 
Table 2. Variation coefficients of traits related to floral organ size of the six populations.

\begin{tabular}{|c|c|c|c|c|c|c|c|c|c|c|c|c|}
\hline \multirow[t]{2}{*}{ Trait } & \multicolumn{2}{|l|}{$P_{1}$} & \multicolumn{2}{|l|}{$\mathrm{P}_{2}$} & \multicolumn{2}{|l|}{$F_{1}$} & \multicolumn{2}{|c|}{$\mathrm{BC}_{1}$} & \multicolumn{2}{|l|}{$\mathrm{BC}_{2}$} & \multicolumn{2}{|l|}{$F_{2}$} \\
\hline & Range (mm) & CV\% & Range (mm) & CV\% & Range (mm) & CV\% & Range (mm) & CV\% & Range (mm) & CV\% & Range (mm) & CV\% \\
\hline $\begin{array}{l}\text { Corolla } \\
\text { width }\end{array}$ & $23.51-28.96$ & 5.09 & $15.77-17.51$ & 2.93 & $19.86-23.51$ & 4.71 & $7.87-30.12$ & 19.07 & $9.68-26.86$ & 14.49 & $9.93-28.85$ & 17.07 \\
\hline $\begin{array}{l}\text { Petal } \\
\text { length }\end{array}$ & $21.09-23.50$ & 3.03 & $13.61-15.35$ & 3.22 & $15.91-20.10$ & 4.60 & $14.37-23.63$ & 8.85 & $11.40-21.68$ & 10.66 & $11.24-23.13$ & 10.79 \\
\hline $\begin{array}{l}\text { Petal } \\
\text { width }\end{array}$ & $8.59-10.77$ & 5.02 & $5.60-6.76$ & 4.59 & $6.54-9.01$ & 7.00 & $5.13-11.08$ & 14.31 & $4.22-10.77$ & 15.38 & $3.31-14.69$ & 18.25 \\
\hline $\begin{array}{l}\text { Long } \\
\text { stamen } \\
\text { length }\end{array}$ & $14.03-15.65$ & 2.90 & $8.27-9.94$ & 4.54 & $11.93-13.54$ & 2.92 & $10.64-16.25$ & 7.92 & $7.79-13.57$ & 8.77 & $8.32-15.20$ & 9.90 \\
\hline $\begin{array}{l}\text { Short } \\
\text { stamen } \\
\text { length }\end{array}$ & $12.52-14.61$ & 3.66 & $7.10-8.73$ & 4.86 & $10.58-12.14$ & 2.89 & $9.47-14.62$ & 7.70 & $6.46-12.01$ & 10.19 & $6.23-13.60$ & 11.08 \\
\hline $\begin{array}{l}\text { Anther } \\
\text { length }\end{array}$ & $3.99-5.05$ & 4.50 & $1.95-2.49$ & 5.00 & $3.28-3.90$ & 3.90 & $3.08-4.80$ & 8.21 & $2.05-4.34$ & 9.90 & $2.17-4.46$ & 10.78 \\
\hline $\begin{array}{l}\text { Style } \\
\text { length }\end{array}$ & $9.65-12.06$ & 5.01 & $5.66-7.54$ & 7.12 & $7.67-10.01$ & 6.92 & $5.88-11.87$ & 14.73 & $4.17-11.29$ & 15.69 & $4.73-12.33$ & 17.38 \\
\hline $\begin{array}{l}\text { Stigma } \\
\text { length }\end{array}$ & $2.78-4.23$ & 8.24 & $0.8-1.71$ & 16.26 & $1.84-2.95$ & 10.73 & $1.15-4.44$ & 25.28 & $0.84-3.20$ & 26.46 & $0.86-3.92$ & 26.93 \\
\hline
\end{tabular}

\section{Frequency distributions of flower-size-related traits in the segregating generations}

The frequency distributions of corolla width, petal length, petal width, long stamen length, short stamen length, anther length, style length, and stigma length in the three segregating generations are shown in Figures 1-8. All the flower-size-related traits showed continuous distribution and were difficult to group, which suggested quantitative inheritance (Figures 1-8).

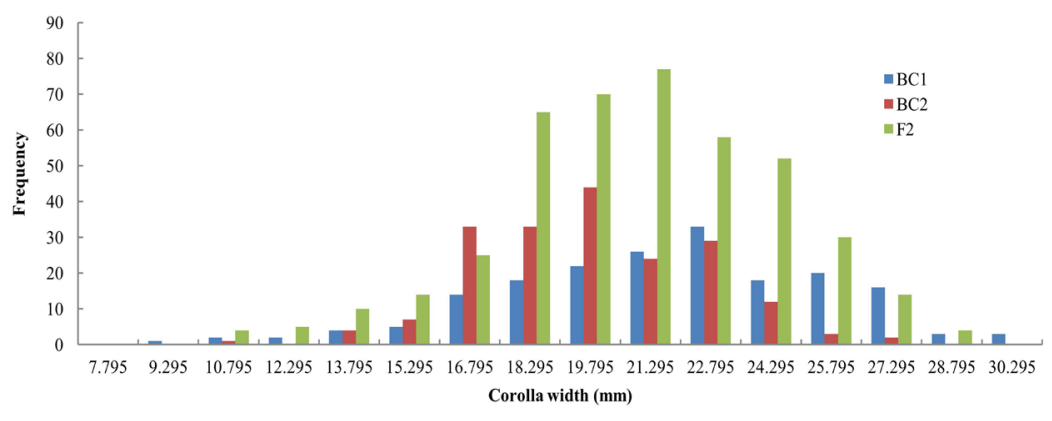

Figure 1. Frequency distribution of corolla width in $\mathrm{BC}_{1}, \mathrm{BC}_{2}$, and $\mathrm{F}_{2}$ segregating populations.

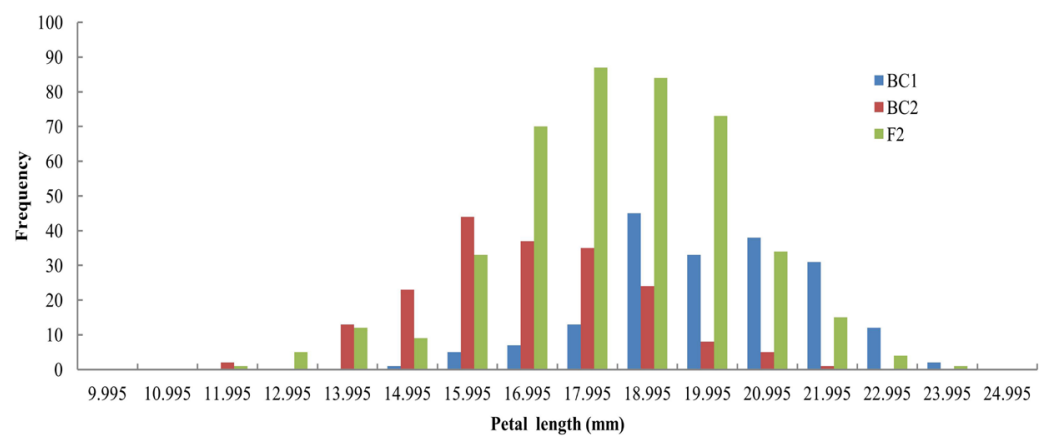

Figure 2. Frequency distribution of petal length in $\mathrm{BC}_{1}, \mathrm{BC}_{2}$, and $\mathrm{F}_{2}$ segregating populations. 


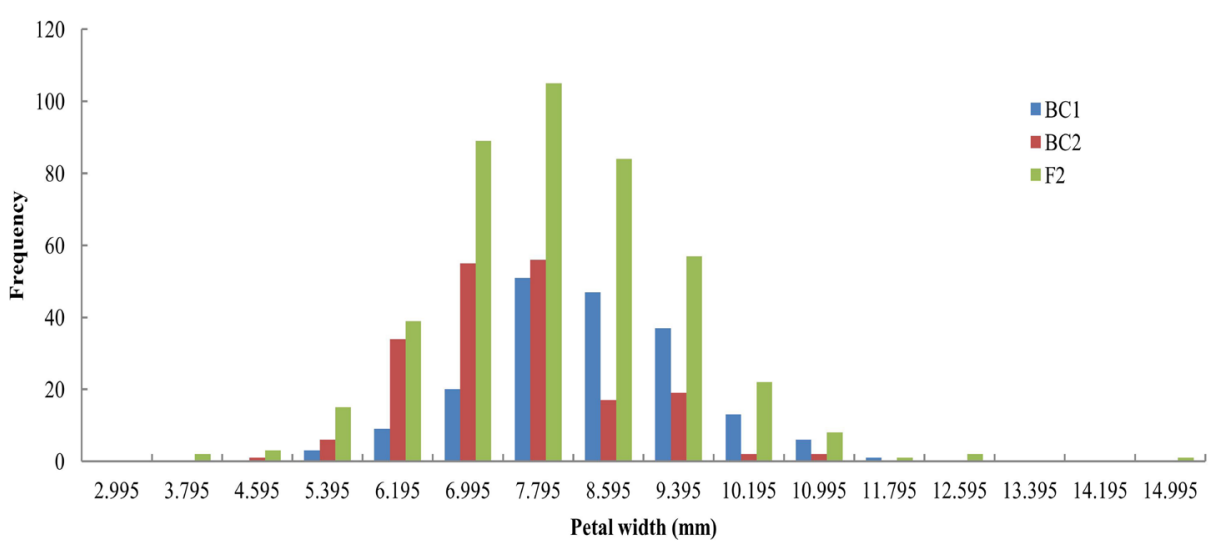

Figure 3. Frequency distribution of petal width in $\mathrm{BC}_{1}, \mathrm{BC}_{2}$, and $\mathrm{F}_{2}$ segregating populations.

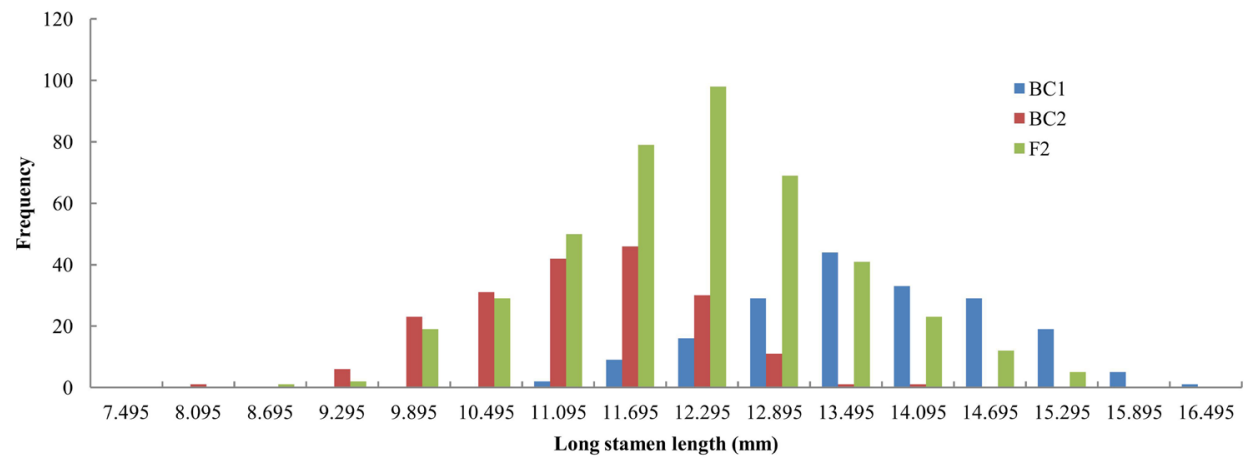

Figure 4. Frequency distribution of long stamen length in $\mathrm{BC}_{1}, \mathrm{BC}_{2}$, and $\mathrm{F}_{2}$ segregating.

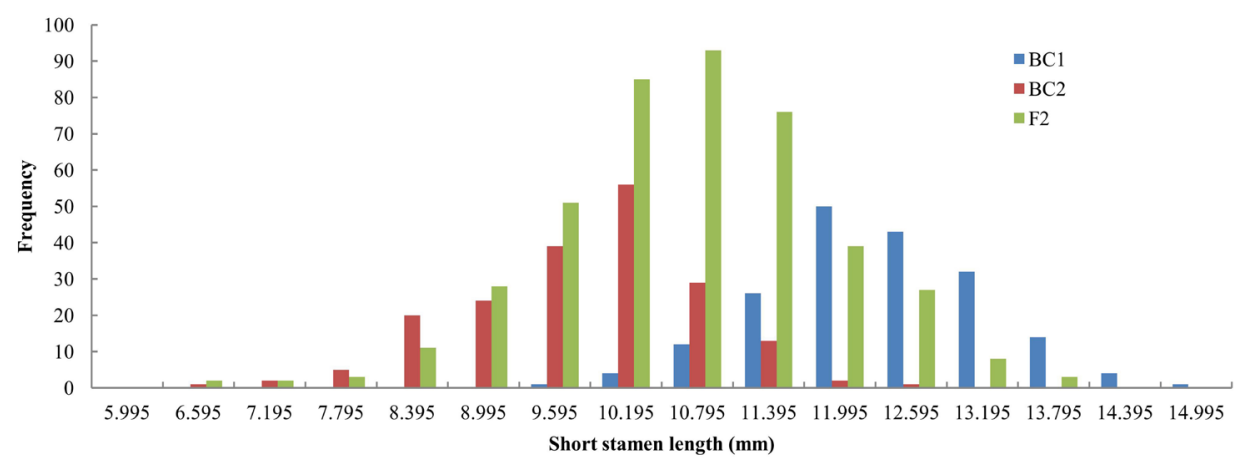

Figure 5. Frequency distribution of short stamen length in $\mathrm{BC}_{1}, \mathrm{BC}_{2}$, and $\mathrm{F}_{2}$ segregating. 


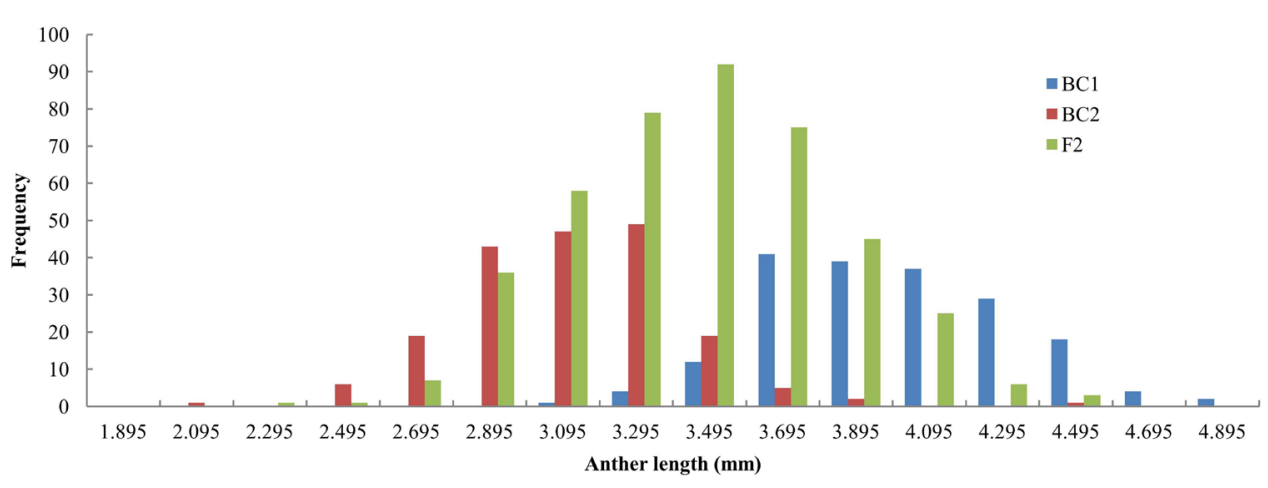

Figure 6. Frequency distribution of anther length in $\mathrm{BC}_{1}, \mathrm{BC}_{2}$, and $\mathrm{F}_{2}$ segregating populations.

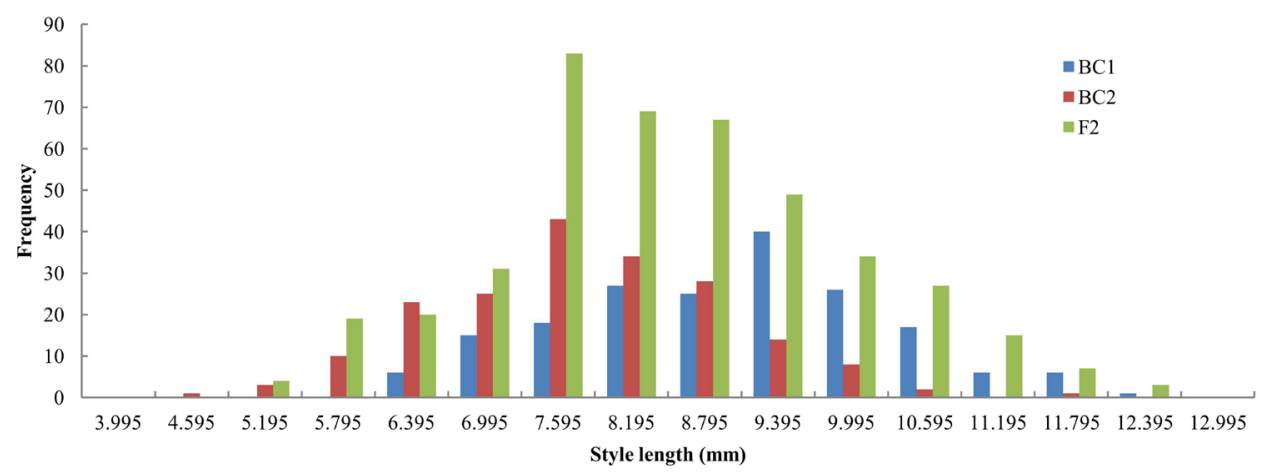

Figure 7. Frequency distribution of style length in $\mathrm{BC}_{1}, \mathrm{BC}_{2}$, and $\mathrm{F}_{2}$ segregating populations.

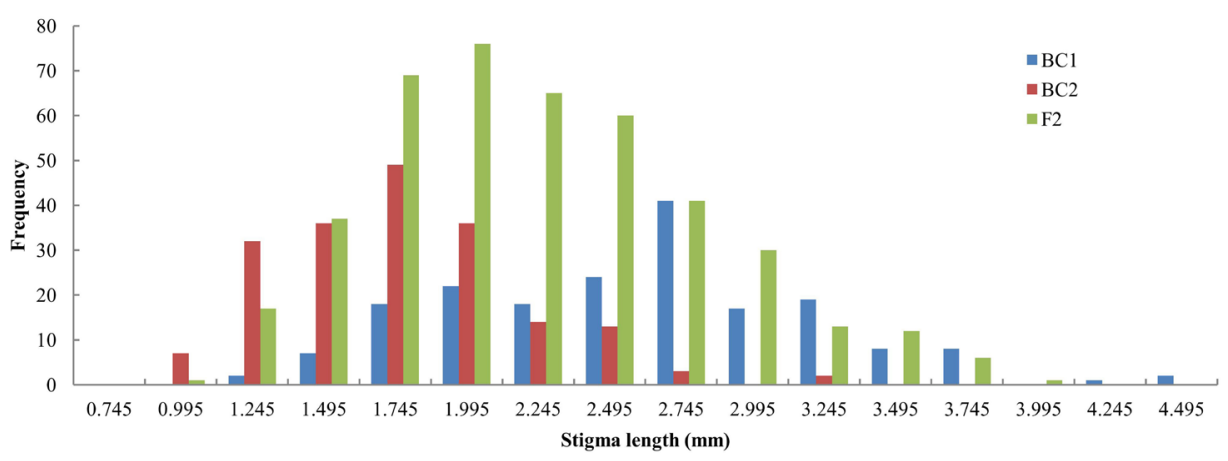

Figure 8. Frequency distribution of stigma length in $\mathrm{BC}_{1}, \mathrm{BC}_{2}$, and $\mathrm{F}_{2}$ segregating populations. 


\section{Inheritance analysis of the flower organ sizes}

The AIC values of the flower-size-related traits in 24 types of genetic models were calculated through the multi-generation joint analysis method of the major gene plus polygene model (Table 3). Three models were selected as the candidate models in each trait because of the relatively lower AIC values. After the evaluations, models C_0, D_0, and E_1 were chosen as the appropriate models for corolla width, petal length, long stamen length, short stamen length, and anther length; models C_0, D_0, and E_0 were the appropriate models for petal width and style length; and models $D_{-} 0, E_{-} 0$, and E_1 were the appropriate models for stigma length, respectively.

Table 3. AIC values in different genetic models of the flower-size-related traits.

\begin{tabular}{|c|c|c|c|c|c|c|c|c|c|}
\hline \multirow[t]{2}{*}{ Model } & \multirow[t]{2}{*}{$\begin{array}{l}\text { Implication of } \\
\text { model }\end{array}$} & \multicolumn{8}{|c|}{ AIC value } \\
\hline & & $\begin{array}{l}\text { Corolla } \\
\text { width }\end{array}$ & $\begin{array}{l}\text { Petal } \\
\text { length }\end{array}$ & $\begin{array}{l}\text { Petal } \\
\text { width }\end{array}$ & $\begin{array}{l}\text { Long } \\
\text { stamen } \\
\text { length }\end{array}$ & $\begin{array}{l}\text { Short } \\
\text { stamen } \\
\text { length }\end{array}$ & $\begin{array}{l}\text { Anther } \\
\text { length }\end{array}$ & $\begin{array}{l}\text { Style } \\
\text { length }\end{array}$ & $\begin{array}{l}\text { Stigma } \\
\text { length }\end{array}$ \\
\hline A_1 & 1MG-AD & 4901.11 & 3748.11 & 2968.84 & 2916.90 & 2864.93 & 1010.68 & 3073.88 & 1446.19 \\
\hline A_2 & $1 \mathrm{MG}-\mathrm{A}$ & 4910.26 & 3746.07 & 2973.57 & 2915.73 & 2864.29 & 1011.88 & 3083.66 & 1491.09 \\
\hline A_3 & 1MG-EAD & 5009.49 & 3986.68 & 3089.58 & 3199.78 & 3163.30 & 1293.86 & 3231.95 & 1724.96 \\
\hline A 4 & 1MG-AEND & 4945.24 & 4030.30 & 3060.89 & 3231.47 & 3135.07 & 1336.17 & 3169.31 & 1595.94 \\
\hline B_1 & 2MG-ADI & 4718.15 & 3617.98 & 2894.75 & 2664.49 & 2620.47 & 532.48 & 3006.39 & 1321.34 \\
\hline B_2 & $2 M G-A D$ & 4889.62 & 3640.53 & 2968.04 & 2704.06 & 2630.75 & 613.77 & 3077.36 & 1386.22 \\
\hline B_3 & 2MG-A & 5090.88 & 3635.89 & 3111.64 & 2707.38 & 2628.12 & 623.72 & 3253.65 & 1618.59 \\
\hline B_ 4 & 2MG-EA & 4911.38 & 3636.46 & 2980.61 & 2713.82 & 2640.06 & 627.85 & 3097.20 & 1445.34 \\
\hline B_5 & 2MG-AED & NA & 3893.45 & 3070.61 & 3001.66 & 2939.90 & 1055.22 & 3212.69 & 1681.19 \\
\hline B_6 & 2MG-EEAD & NA & 3891.45 & NA & 2999.66 & 2937.90 & 1053.22 & 3210.69 & 1679.19 \\
\hline C_0 & PG-ADI & 4662.50 & 3574.28 & 2835.33 & 2596.11 & 2530.22 & 425.02 & 2986.94 & 1336.74 \\
\hline C 1 & PG-AD & $\overline{4773.71}$ & $\overline{3609.84}$ & $\overline{2913.72}$ & $\overline{2671.40}$ & 2641.57 & $\overline{531.29}$ & 3071.88 & 1419.62 \\
\hline D_0 & MX1-AD-ADI & 4664.17 & 3575.87 & 2838.17 & 2600.11 & 2533.61 & 429.02 & 2985.76 & 1319.99 \\
\hline D_1 & MX1-AD-AD & $\overline{4738.25}$ & 3595.85 & 2900.65 & $\overline{2624.40}$ & $\overline{2559.77}$ & $\overline{441.02}$ & $\overline{3052.61}$ & $\overline{1372.37}$ \\
\hline D_2 & MX1-A-AD & 4735.01 & 3593.85 & 2898.66 & 2622.40 & 2557.77 & 439.02 & 3049.30 & 1370.37 \\
\hline D 3 & MX1-EAD-AD & 4735.17 & 3594.40 & 2901.35 & 2623.28 & 2559.05 & 463.10 & 3054.80 & 1393.37 \\
\hline D_4 & MX1-AEND-AD & 4737.79 & 3597.32 & 2900.05 & 2623.27 & 2558.98 & 462.74 & 3054.64 & 1340.40 \\
\hline E_0 & MX2-ADI-ADI & 4674.82 & 3585.83 & 2841.84 & 2609.29 & 2536.86 & 437.45 & 2987.90 & 1317.90 \\
\hline E_1 & MX2-ADI-AD & 4668.84 & 3564.74 & $\overline{2844.67}$ & $\underline{2603.27}$ & 2534.58 & 435.03 & $\overline{2988.23}$ & $\overline{1312.74}$ \\
\hline E2 2 & MX2-AD-AD & $\overline{4770.32}$ & $\overline{3615.93}$ & 2883.19 & 2659.60 & 2645.55 & $\overline{534.15}$ & 3048.83 & 1362.06 \\
\hline E_3 & $M X 2-A-A D$ & 4693.47 & 3581.44 & 2862.89 & 2603.56 & 2554.57 & 502.22 & 2995.77 & 1322.17 \\
\hline E_4 & MX2-EAED-AD & 4774.59 & 3611.18 & 2915.15 & 2641.35 & 2641.81 & 531.02 & 3039.57 & 1391.35 \\
\hline E_5 & MX2-AED-AD & 4768.32 & 3606.64 & 2917.65 & 2675.05 & 2635.62 & 534.89 & 3075.78 & 1423.57 \\
\hline E_6 & MX2-EEAD-AD & NA & NA & NA & NA & NA & NA & NA & NA \\
\hline
\end{tabular}

MG: major gene model; PG: polygenic model; MX: mixed major gene plus polygenes model; A: additive effect; $D$ : dominance effect; $\mathrm{E}$ : equal; $\mathrm{N}$ : negative; I: epistatic interaction; e.g., Model E_1=MX2-ADI-AD, means two major genes of additive-dominance-epistasis effects plus additive-dominance polygene. NA: not available. The minimum AIC value is represented by the underline, showing the appropriate model.

Five statistical parameters: $U_{1}{ }^{2}, U_{2}{ }^{2}, U_{3}{ }^{2}$ (homogeneity test), ${ }_{n} W^{2}$ (Smirnov test), and $D_{n}$ (Kolmogorov test) were used to determine the best models, according to the fitness testing (Table 4). Five statistics in the candidate models of corolla width, petal length, petal width, short stamen length, anther length, style length, and stigma length passed all the tests of significance. The D_0 model reached a significant level $(P=0.05)$ with four statistical parameters, the C_0 and E_1 models passed all the significance tests in the long stamen length candidate models (Table 4). 
Table 4. Tests of goodness-of-fit in the candidate models for the flower-size-related traits.

\begin{tabular}{|c|c|c|c|c|c|c|c|}
\hline Trait & Model & Generation & $U_{1}{ }^{2}$ & $U_{2}{ }^{2}$ & $U_{3}{ }^{2}$ & ${ }_{n} W^{2}$ & $D_{\mathrm{n}}$ \\
\hline \multirow[t]{9}{*}{ Corolla width } & C_0 & $\mathrm{BC}_{1}$ & $0.166(0.6838)$ & $0.126(0.7221)$ & $0.024(0.8768)$ & $0.0637(>0.05)$ & $0.0572(>0.05)$ \\
\hline & & $\mathrm{BC}_{2}$ & $0.025(0.8733)$ & $0.006(0.9359)$ & $0.088(0.7672)$ & $0.0632(>0.05)$ & $0.0419(>0.05)$ \\
\hline & & $\mathrm{F}_{2}$ & $0.142(0.7060)$ & $0.060(0.8058)$ & $0.228(0.6331)$ & $0.0586(>0.05)$ & $0.0289(>0.05)$ \\
\hline & D_0 & $\mathrm{BC}_{1}$ & $0.166(0.6838)$ & $0.126(0.7222)$ & $0.024(0.8765)$ & $0.0638(>0.05)$ & $0.0572(>0.05)$ \\
\hline & & $\mathrm{BC}_{2}$ & $0.066(0.7969)$ & $0.099(0.7536)$ & $0.067(0.7956)$ & $0.0601(>0.05)$ & $0.0411(>0.05)$ \\
\hline & & $F_{2}$ & $0.056(0.8128)$ & $0.015(0.9016)$ & $0.179(0.6725)$ & $0.0494(>0.05)$ & $0.0305(>0.05)$ \\
\hline & E_1 & $\mathrm{BC}_{1}$ & $1.224(0.2686)$ & $1.973(0.1601)$ & $1.778(0.1824)$ & $0.2029(>0.05)$ & $0.0840(>0.05)$ \\
\hline & & $\mathrm{BC}_{2}$ & $0.004(0.9502)$ & $0.000(0.9996)$ & $0.057(0.8105)$ & $0.0511(>0.05)$ & $0.0427(>0.05)$ \\
\hline & & $F_{2}$ & $0.085(0.7712)$ & $0.035(0.8506)$ & $0.139(0.7093)$ & $0.0657(>0.05)$ & $0.0360(>0.05)$ \\
\hline \multirow[t]{9}{*}{ Petal length } & C_0 & $\mathrm{BC}_{1}$ & $0.059(0.8087)$ & $0.097(0.7559)$ & $0.093(0.7599)$ & $0.0925(>0.05)$ & $0.0494(>0.05)$ \\
\hline & & $\mathrm{BC}_{2}$ & $0.022(0.8815)$ & $0.013(0.9094)$ & $0.015(0.9029)$ & $0.0501(>0.05)$ & $0.0511(>0.05)$ \\
\hline & & $F_{2}$ & $0.176(0.6750)$ & $0.039(0.8443)$ & $0.703(0.4018)$ & $0.0739(>0.05)$ & $0.0309(>0.05)$ \\
\hline & D_0 & $\mathrm{BC}_{1}$ & $0.059(0.8087)$ & $0.097(0.7559)$ & $0.093(0.7599)$ & $0.0925(>0.05)$ & $0.0494(>0.05)$ \\
\hline & & $\mathrm{BC}_{2}$ & $0.043(0.8359)$ & $0.073(0.7871)$ & $0.077(0.7807)$ & $0.0498(>0.05)$ & $0.0498(>0.05)$ \\
\hline & & $F_{2}$ & $0.080(0.7778)$ & $0.005(0.9456)$ & $0.672(0.4123)$ & $0.0595(>0.05)$ & $0.0328(>0.05)$ \\
\hline & E_1 & $\mathrm{BC}_{1}$ & $0.028(0.8669)$ & $0.021(0.8837)$ & $0.004(0.9491)$ & $0.0955(>0.05)$ & $0.0578(>0.05)$ \\
\hline & & $\mathrm{BC}_{2}$ & $1.068(0.3014)$ & $0.949(0.3299)$ & $0.011(0.9166)$ & $0.1323(>0.05)$ & $0.0548(>0.05)$ \\
\hline & & $F_{2}$ & $0.035(0.8521)$ & $0.026(0.8723)$ & $0.006(0.9368)$ & $0.0211(>0.05)$ & $0.0213(>0.05)$ \\
\hline \multirow[t]{9}{*}{ Petal width } & C_0 & $\mathrm{BC}_{1}$ & $0.000(0.9974)$ & $0.001(0.9734)$ & $0.021(0.8839)$ & $0.0365(>0.05)$ & $0.0369(>0.05)$ \\
\hline & & $\mathrm{BC}_{2}$ & $0.568(0.4512)$ & $0.720(0.3961)$ & $0.227(0.6341)$ & $0.2349(>0.05)$ & $0.0675(>0.05)$ \\
\hline & & $F_{2}$ & $0.159(0.6898)$ & $0.442(0.5060)$ & $1.242(0.2651)$ & $0.0815(>0.05)$ & $0.0303(>0.05)$ \\
\hline & D_0 & $\mathrm{BC}_{1}$ & $0.000(0.9956)$ & $0.000(0.9826)$ & $0.004(0.9479)$ & $0.0324(>0.05)$ & $0.0332(>0.05)$ \\
\hline & & $\mathrm{BC}_{2}$ & $0.568(0.4512)$ & $0.720(0.3961)$ & $0.227(0.6341)$ & $0.2349(>0.05)$ & $0.0675(>0.05)$ \\
\hline & & $F_{2}$ & $0.118(0.7308)$ & $0.381(0.5372)$ & $1.290(0.2560)$ & $0.0696(>0.05)$ & $0.0290(>0.05)$ \\
\hline & E_0 & $\mathrm{BC}_{1}$ & $0.042(0.8385)$ & $0.011(0.9166)$ & $0.137(0.7109)$ & $0.0477(>0.05)$ & $0.0374(>0.05)$ \\
\hline & & $\mathrm{BC}_{2}$ & $0.305(0.5807)$ & $0.384(0.5357)$ & $0.114(0.7356)$ & $0.0862(>0.05)$ & $0.0590(>0.05)$ \\
\hline & & $\mathrm{F}_{2}$ & $0.112(0.7379)$ & $0.446(0.5042)$ & $1.892(0.1690)$ & $0.0791(>0.05)$ & $0.0324(>0.05)$ \\
\hline \multirow[t]{9}{*}{$\begin{array}{l}\text { Long stamen } \\
\text { length }\end{array}$} & C_0 & $\mathrm{BC}_{1}$ & $0.015(0.9029)$ & $0.041(0.8396)$ & $0.113(0.7362)$ & $0.0209(>0.05)$ & $0.0301(>0.05)$ \\
\hline & & $\mathrm{BC}_{2}$ & $0.046(0.8303)$ & $0.085(0.7703)$ & $0.114(0.7355)$ & $0.0439(>0.05)$ & $0.0375(>0.05)$ \\
\hline & & $\mathrm{F}_{2}$ & $0.006(0.9397)$ & $0.041(0.8388)$ & $0.271(0.6026)$ & $0.0578(>0.05)$ & $0.0335(>0.05)$ \\
\hline & D_0 & $\mathrm{BC}_{1}$ & $21.101(0.0000)^{*}$ & $19.443(0.0000)^{*}$ & $0.023(0.8783)$ & $2.0259(<0.05)^{*}$ & $0.1597(<0.05)^{*}$ \\
\hline & & $\mathrm{BC}_{2}$ & $0.110(0.7401)$ & $0.062(0.8037)$ & $0.084(0.7715)$ & $0.0388(>0.05)$ & $0.0474(>0.05)$ \\
\hline & & $F_{2}$ & $0.006(0.9404)$ & $0.041(0.8394)$ & $0.272(0.6021)$ & $0.0579(>0.05)$ & $0.0335(>0.05)$ \\
\hline & E_1 & $\mathrm{BC}_{1}$ & $0.019(0.8910)$ & $0.001(0.9718)$ & $0.451(0.5017)$ & $0.0352(>0.05)$ & $0.0424(>0.05)$ \\
\hline & & $\mathrm{BC}_{2}$ & $0.004(0.9507)$ & $0.016(0.8993)$ & $0.071(0.7898)$ & $0.0384(>0.05)$ & $0.0378(>0.05)$ \\
\hline & & $F_{2}$ & $0.015(0.9040)$ & $0.009(0.9249)$ & $0.008(0.9285)$ & $0.0348(>0.05)$ & $0.0237(>0.05)$ \\
\hline \multirow{9}{*}{$\begin{array}{l}\text { Short stamen } \\
\text { length }\end{array}$} & C_0 & $\mathrm{BC}_{1}$ & $0.002(0.9618)$ & $0.001(0.9788)$ & $0.006(0.9370)$ & $0.0529(>0.05)$ & $0.0412(>0.05)$ \\
\hline & & $\mathrm{BC}_{2}$ & $0.188(0.6643)$ & $0.191(0.6617)$ & $0.005(0.9447)$ & $0.1338(>0.05)$ & $0.0721(>0.05)$ \\
\hline & & $\mathrm{F}_{2}$ & $0.025(0.8742)$ & $0.009(0.9252)$ & $0.977(0.3229)$ & $0.0725(>0.05)$ & $0.0362(>0.05)$ \\
\hline & D_0 & $\mathrm{BC}_{1}$ & $0.002(0.9619)$ & $0.001(0.9788)$ & $0.006(0.9370)$ & $0.0529(>0.05)$ & $0.0412(>0.05)$ \\
\hline & & $\mathrm{BC}_{2}$ & $0.250(0.6170)$ & $0.225(0.6354)$ & $0.002(0.9681)$ & $0.1446(>0.05)$ & $0.0750(>0.05)$ \\
\hline & & $F_{2}$ & $0.008(0.9279)$ & $0.026(0.8711)$ & $0.999(0.3175)$ & $0.0723(>0.05)$ & $0.0343(>0.05)$ \\
\hline & E_1 & $\mathrm{BC}_{1}$ & $0.339(0.5606)$ & $0.240(0.6241)$ & $0.086(0.7691)$ & $0.0838(>0.05)$ & $0.0572(>0.05)$ \\
\hline & & $\mathrm{BC}_{2}$ & $1.284(0.2572)$ & $1.020(0.3125)$ & $0.121(0.7278)$ & $0.2016(>0.05)$ & $0.0825(>0.05)$ \\
\hline & & $F_{2}$ & $1.288(0.2564)$ & $1.873(0.1712)$ & $1.163(0.2808)$ & $0.2208(>0.05)$ & $0.0498(>0.05)$ \\
\hline \multirow[t]{9}{*}{ Anther length } & C_0 & $\mathrm{BC}_{1}$ & $0.073(0.7864)$ & $0.016(0.9008)$ & $0.303(0.5818)$ & $0.0824(>0.05)$ & $0.0530(>0.05)$ \\
\hline & & $\mathrm{BC}_{2}$ & $0.017(0.8956)$ & $0.161(0.6881)$ & $1.205(0.2723)$ & $0.0598(>0.05)$ & $0.0549(>0.05)$ \\
\hline & & $\mathrm{F}_{2}$ & $0.009(0.9265)$ & $0.001(0.9818)$ & $0.071(0.7903)$ & $0.0346(>0.05)$ & $0.0319(>0.05)$ \\
\hline & D_0 & $\mathrm{BC}_{1}$ & $0.074(0.7863)$ & $0.016(0.9004)$ & $0.302(0.5826)$ & $0.0824(>0.05)$ & $0.0530(>0.05)$ \\
\hline & & $\mathrm{BC}_{2}$ & $0.017(0.8953)$ & $0.162(0.6876)$ & $1.208(0.2718)$ & $0.0599(>0.05)$ & $0.0549(>0.05)$ \\
\hline & & $F_{2}$ & $0.008(0.9268)$ & $0.001(0.9821)$ & $0.071(0.7902)$ & $0.0346(>0.05)$ & $0.0319(>0.05)$ \\
\hline & E_1 & $\mathrm{BC}_{1}$ & $0.047(0.8280)$ & $0.045(0.8312)$ & $0.000(0.9910)$ & $0.0309(>0.05)$ & $0.0421(>0.05)$ \\
\hline & & $\mathrm{BC}_{2}$ & $0.919(0.3378)$ & $0.311(0.5771)$ & $2.195(0.1384)$ & $0.1878(>0.05)$ & $0.0648(>0.05)$ \\
\hline & & $\mathrm{F}_{2}$ & $0.256(0.6130)$ & $0.315(0.5747)$ & $0.082(0.7751)$ & $0.0618(>0.05)$ & $0.0318(>0.05)$ \\
\hline \multirow[t]{9}{*}{ Style length } & C_O & $\mathrm{BC}_{1}$ & $0.003(0.9563)$ & $0.024(0.8777)$ & $0.162(0.6869)$ & $0.0562(>0.05)$ & $0.0601(>0.05)$ \\
\hline & & $\mathrm{BC}_{2}$ & $0.013(0.9088)$ & $0.007(0.9314)$ & $0.010(0.9208)$ & $0.0146(>0.05)$ & $0.0282(>0.05)$ \\
\hline & & $\mathrm{F}_{2}$ & $0.142(0.7067)$ & $0.132(0.7165)$ & $0.000(0.9963)$ & $0.1571(>0.05)$ & $0.0524(>0.05)$ \\
\hline & D_0 & $\mathrm{BC}_{1}$ & $0.014(0.9060)$ & $0.004(0.9466)$ & $0.036(0.8497)$ & $0.0627(>0.05)$ & $0.0647(>0.05)$ \\
\hline & & $\mathrm{BC}_{2}$ & $0.014(0.9045)$ & $0.010(0.9210)$ & $0.005(0.9459)$ & $0.0145(>0.05)$ & $0.0277(>0.05)$ \\
\hline & & $F_{2}$ & $0.001(0.9771)$ & $0.007(0.9332)$ & $0.050(0.8226)$ & $0.0905(>0.05)$ & $0.0369(>0.05)$ \\
\hline & E_0 & $\mathrm{BC}_{1}$ & $0.114(0.7359)$ & $0.178(0.6728)$ & $0.147(0.7015)$ & $0.0547(>0.05)$ & $0.0450(>0.05)$ \\
\hline & & $\mathrm{BC}_{2}$ & $0.145(0.7035)$ & $0.233(0.6295)$ & $0.207(0.6488)$ & $0.0475(>0.05)$ & $0.0398(>0.05)$ \\
\hline & & $\mathrm{F}_{2}$ & $0.202(0.6529)$ & $0.058(0.8095)$ & $0.605(0.4366)$ & $0.0852(>0.05)$ & $0.0363(>0.05)$ \\
\hline
\end{tabular}

Continued on next page 


Table 4. Continued.
\begin{tabular}{l|c|c|c|c|c|c|c}
\hline Trait & Model & Generation & $U_{1}{ }^{2}$ & $U_{2}{ }^{2}$ & $U_{3}{ }^{2}$ & ${ }^{2} W^{2}$ & $D_{\mathrm{n}}$ \\
\hline Stigma length & $\mathrm{D} \_0$ & $\mathrm{BC}_{1}$ & $0.197(0.6569)$ & $0.420(0.5168)$ & $0.762(0.3827)$ & $0.0933(>0.05)$ & $0.0588(>0.05)$ \\
\hline & & $\mathrm{BC}_{2}$ & $0.421(0.5162)$ & $0.459(0.4983)$ & $0.038(0.8461)$ & $0.1106(>0.05)$ & $0.0469(>0.05)$ \\
\hline & & $\mathrm{F}_{2}$ & $0.132(0.7168)$ & $0.066(0.7969)$ & $0.141(0.7076)$ & $0.0505(>0.05)$ & $0.0289(>0.05)$ \\
\hline & $\mathrm{E} \_0$ & $\mathrm{BC}_{1}$ & $0.045(0.8318)$ & $0.104(0.7472)$ & $0.218(0.6407)$ & $0.0785(>0.05)$ & $0.0484(>0.05)$ \\
\hline & & $\mathrm{BC}_{2}$ & $0.234(0.6285)$ & $0.262(0.6089)$ & $0.030(0.8632)$ & $0.0596(>0.05)$ & $0.0446(>0.05)$ \\
\hline & & $\mathrm{F}_{2}$ & $0.037(0.8467)$ & $0.029(0.8649)$ & $0.005(0.9454)$ & $0.0341(>0.05)$ & $0.0304(>0.05)$ \\
\hline & $\mathrm{E} \_1$ & $\mathrm{BC}_{1}$ & $0.154(0.6946)$ & $0.298(0.5853)$ & $0.438(0.5079)$ & $0.0917(>0.05)$ & $0.0504(>0.05)$ \\
\hline & & $\mathrm{BC}_{2}$ & $0.268(0.6049)$ & $0.392(0.5313)$ & $0.251(0.6165)$ & $0.0726(>0.05)$ & $0.0489(>0.05)$ \\
\hline & & $\mathrm{F}_{2}$ & $0.027(0.8685)$ & $0.006(0.9406)$ & $0.118(0.7314)$ & $0.0260(>0.05)$ & $0.0216(>0.05)$ \\
\hline
\end{tabular}

Significance threshold of ${ }_{n} W^{2}$ at the 0.05 level was 0.461 . Numbers in parentheses are the distribution values in theory, '*'indicates a significant difference at $\mathrm{P}<0.05$.

Thus, combining the AIC values (Table 3) and the goodness-of-fit test results (Table 4), model C_0 was determined as the best genetic model for corolla width, petal width, long stamen length, short stamen length, and anther length; E_1 was the best genetic model for petal length and stigma length; D_0 was the best genetic model for style length, respectively (Table 5).

Table 5. Best genetic model of the flower-size-related traits.

\begin{tabular}{l|c|l}
\hline Traits & Model & Model analysis \\
\hline Corolla width & C_0 & PG-ADI (additive-dominance-epistasis polygene) \\
\hline Petal length & E_1 & MX2-ADI-AD (two major genes of additive-dominance-epistasis effects plus additive-dominance polygene) \\
\hline Petal width & C_0 & PG-ADI (additive-dominance-epistasis polygene) \\
\hline Long stamen length & C_0 & PG-ADI (additive-dominance-epistasis polygene) \\
\hline Short stamen length & C_0 & PG-ADI (additive-dominance-epistasis polygene) \\
\hline Anther length & C_0 & PG-ADI (additive-dominance-epistasis polygene) \\
\hline Style length & D_0 & MX1-AD-ADI (one major gene of additive-dominance effects plus additive-dominance-epistasis polygene) \\
\hline Stigma length & E_1 & MX2-ADI-AD (two major genes of additive-dominance-epistasis effects plus additive-dominance polygene) \\
\hline
\end{tabular}

\section{Estimation of genetic parameters}

The first- and the second-order genetic parameters were estimated using the formulas of the IECM method (Gai et al., 2003). The maximum likelihood values of the parameters indicate the best model (Tables 6 and 7).

Table 6. Estimates of the first-order genetic parameters for the best models of the flower-size-related traits.

\begin{tabular}{|c|c|c|c|c|c|c|c|c|c|c|c|}
\hline \multirow{2}{*}{ Traits and model } & \multicolumn{11}{|c|}{ First-order genetic parameters } \\
\hline & $m$ & $d_{\mathrm{a} / \mathrm{d}}$ & $d_{\mathrm{b}}$ & $h_{a} / h$ & $h_{\mathrm{b}}$ & $i$ & jab & $j_{\text {ba }}$ & 1 & {$[d]$} & {$[h]$} \\
\hline Corolla width (C_0) & - & - & - & - & - & - & - & - & - & - & - \\
\hline Petal length (E_1) & 18.08 & 2.89 & -0.96 & -0.70 & 0.28 & 0.26 & -2.05 & 0.78 & 1.68 & 2.03 & -0.77 \\
\hline Petal width (C_0) & - & - & - & - & - & - & - & - & - & - & - \\
\hline Long stamen length (C_0) & - & - & - & - & - & - & - & - & - & - & - \\
\hline Short stamen length (C_0) & - & - & - & - & - & - & - & - & - & - & - \\
\hline Anther length (C_0) & - & - & - & - & - & - & - & - & - & - & - \\
\hline Style length (D_0) & - & 1.20 & - & -0.46 & - & - & - & - & - & - & - \\
\hline Stigma length (E_1) & 2.65 & 0.48 & 0.04 & -0.81 & -0.80 & -0.23 & -0.41 & 0.02 & 1.46 & 0.51 & -0.19 \\
\hline
\end{tabular}

The subscripts $\mathrm{a}$ and $\mathrm{b}$ refer to two major genes. $d$ : additive effect; $d_{\mathrm{a}}$ : additive effect of the first major gene; $d_{\mathrm{b}}$ : additive effect of the second major gene; $h$ : dominant effect; $h_{\mathrm{a}}$ : dominant effect of the first major gene; $h_{\mathrm{b}}$ : dominant effect of the second major gene; $i$ : epistatic effect value of additive $\mathrm{x}$ additive between $d_{\mathrm{a}}$ and $d_{\mathrm{b}} ; j_{\mathrm{ab}}$ : epistatic effect value of additive $\mathrm{x}$ dominant between $d_{\mathrm{a}}$ and $h_{\mathrm{b}} ; j_{\mathrm{ba}}$ : epistatic effect value of dominant $\mathrm{x}$ additive between $h_{\mathrm{a}}$ and $d_{\mathrm{b}}$; l: epistatic effect value of dominant $\mathrm{x}$ dominant between $h_{\mathrm{a}}$ and $h_{\mathrm{b}}$; [d]: additive effect of polygene; [h]: dominant effect of polygene; '-' indicates no data. 
Table 7. Estimates of the second-order genetic parameters for the best models of the flower-size-related traits.

\begin{tabular}{l|c|c|c|c|c|c|c}
\hline Traits and & Generation & \multicolumn{7}{|c}{ Second-order genetic parameters } \\
\hline model & & $\sigma_{\mathrm{p}}{ }^{2}$ & $\sigma_{\mathrm{mg}}{ }^{2}$ & $\sigma_{\mathrm{pg}}{ }^{2}$ & $\sigma_{\mathrm{e}}{ }^{2}$ & $h_{\mathrm{mg}}{ }^{2}(\%)$ & $h_{\mathrm{pg}^{2}}{ }^{(\%)}$ \\
\hline Corolla width & $\mathrm{BC}_{1}$ & 15.9304 & - & 14.9362 & 0.9942 & - & 93.76 \\
\hline (C_0) & $\mathrm{BC}_{2}$ & 7.5326 & - & 6.5384 & 0.9942 & - & 86.80 \\
\hline & $\mathrm{F}_{2}$ & 11.8731 & - & 10.8790 & 0.9942 & - & 91.63 \\
\hline Petal length & $\mathrm{BC}_{1}$ & 3.0241 & 1.1686 & 1.3991 & 0.4563 & 38.64 & 46.27 \\
\hline (E_1) & $\mathrm{BC}_{2}$ & 3.0761 & 1.1079 & 1.5120 & 0.4563 & 36.01 & 49.15 \\
\hline Petal width & $\mathrm{F}_{2}$ & 3.7292 & 2.9525 & 0.3204 & 0.4563 & 79.17 & 8.59 \\
\hline (C_0) & $\mathrm{BC}_{1}$ & 1.3008 & - & 1.0956 & 0.2052 & - & 84.22 \\
\hline Long stamen length & $\mathrm{BC}_{2}$ & 1.1785 & - & 0.9733 & 0.2052 & - & 82.59 \\
\hline (C_0) & $\mathrm{F}_{2}$ & 1.8907 & - & 1.6854 & 0.2052 & - & 89.14 \\
\hline Short stamen length & $\mathrm{BC}_{1}$ & 1.1258 & - & 0.9619 & 0.1639 & - & 85.44 \\
\hline (C_0) & $\mathrm{BC}_{2}$ & 0.9137 & - & 0.7498 & 0.1639 & - & 82.07 \\
\hline Anther length & $\mathrm{F}_{2}$ & 1.3874 & - & 1.2235 & 0.1639 & - & 88.19 \\
\hline (C_0) & $\mathrm{BC}_{1}$ & 0.8564 & - & 0.6913 & 0.1651 & - & 80.72 \\
\hline & $\mathrm{BC}_{2}$ & 0.9397 & - & 0.7745 & 0.1651 & - & 82.43 \\
\hline Style length & $\mathrm{F}_{2}$ & 1.3203 & - & 1.1552 & 0.1651 & - & 87.49 \\
\hline (D_0) & $\mathrm{BC}_{1}$ & 0.1022 & - & 0.0783 & 0.0239 & - & 76.58 \\
\hline & $\mathrm{BC}_{2}$ & 0.0880 & - & 0.0641 & 0.0239 & - & 72.80 \\
\hline Stigma length & $\mathrm{F}_{2}$ & 0.1312 & - & 0.1072 & 0.0239 & - & 81.76 \\
\hline (E_1) & $\mathrm{BC}_{1}$ & 1.6623 & 0.6749 & 0.6957 & 0.2917 & 40.60 & 41.85 \\
\hline & $\mathrm{BC}_{2}$ & 1.3751 & 0.1423 & 0.9412 & 0.2917 & 10.35 & 68.44 \\
\hline
\end{tabular}

$\sigma_{\mathrm{p}}{ }^{2}$ : phenotypic variance; $\sigma_{\mathrm{mg}}{ }^{2}$ : major gene variance; $\sigma_{\mathrm{pg}}{ }^{2}:$ polygene variance; $\sigma_{\mathrm{e}}{ }^{2}$ : environmental variance; $h_{\mathrm{mg}}{ }^{2}$ : heritability of major gene; $h_{\mathrm{pg}}^{2}$ : heritability of polygene; '-' indicates no data.

The C_0 model was the best for corolla width, petal width, long stamen length, short stamen length, and anther length. The heritability of these traits in the $\mathrm{BC}_{1}, \mathrm{BC}_{2}$, and $\mathrm{F}_{2}$ segregation generations were high: corolla width varied from 86.80 to $93.76 \%$, petal width varied from 82.59 to $89.14 \%$, long stamen length varied from 82.07 to $88.19 \%$, short stamen length varied from 80.72 to $87.49 \%$, and anther length varied from 72.80 to $81.76 \%$ (Table 7 ).

Petal length was governed by the E-1 model (Table 6): in the major genes, the additive effect of the first major gene was positive $\left(d_{\mathrm{a}}=2.89\right)$ and that of the second major gene was negative $\left(d_{\mathrm{b}}=-0.96\right)$. The additive genetic contribution rate of the first major gene was larger $\left(\left|d_{\mathrm{a}}\right|>\right.$ $\left.\left|d_{\mathrm{b}}\right|\right)$; the additive effects of the two major genes were higher than the dominant effects $\left(\left|d_{\mathrm{a}}\right|+\left|d_{\mathrm{b}}\right|>\right.$ $\left.\left|h_{\mathrm{a}}\right|+\left|h_{\mathrm{b}}\right|\right)$, which showed that the inheritance of petal length was mainly due to a positive additive effect. Short petal to long petal showed partial dominance $(-1<h / d<0)$. The epistatic effect values of additive $\mathrm{x}$ additive $(i=0.26)$ and dominance $\mathrm{x}$ dominance $(I=1.68)$ were positive; the epistatic effect value of additive $x$ dominant was negative with a strong effect $\left(j_{a b}=-2.05\right)$ and dominant $x$ additive was positive with a weak effect $\left(j_{\mathrm{ba}}=0.78\right)$. Considering all the interactions between the two major genes, the epistasis of the cumulative effect was positive. The heritability of major genes in the $\mathrm{BC}_{1}, \mathrm{BC}_{2}$, and $\mathrm{F}_{2}$ generations were $38.64,36.01$, and $79.17 \%$, respectively; the heritability of polygenes in $\mathrm{BC}_{1}, \mathrm{BC}_{2}$, and $\mathrm{F}_{2}$ generations were $46.27,49.15$, and $8.59 \%$, respectively (Table 7). The ratios of major gene heritability among the total heritability of the $\mathrm{BC}_{1}, \mathrm{BC}_{2}$, and $\mathrm{F}_{2}$ generations were $0.455,0.423$, and 0.902 , respectively. Therefore, major positive genes for petal length were selected in the $\mathrm{F}_{2}$ generation with high efficiency.

Style length was controlled by the D_0 model. The additive effect of the major gene was 
positive $(d=1.20)$ and the dominant effect was negative $(h=-0.46)$. The additive effects of the major genes were higher than dominant effects $(|d|>|h|)$ and the short style to long style showed partial dominance $(-1<h / d<0)$. The heritability of major genes in the $\mathrm{BC}_{1}, \mathrm{BC}_{2}$, and $\mathrm{F}_{2}$ were $40.60,10.35$, and $38.44 \%$, respectively. The polygene heritability varied from 41.85 to $68.44 \%$. The ratio of major gene heritability among the total heritability of the $\mathrm{BC}_{1}, \mathrm{BC}_{2}$, and $\mathrm{F}_{2}$ generations were $0.492,0.131$, and 0.449 , respectively. Thus, it could be inferred that the style length was mainly controlled by polygenes.

Two major genes controlled the stigma length (Table 6). The additive effect of the first gene $\left(d_{a}=0.48\right)$ was higher than that of the second gene $\left(d_{b}=0.04\right)$. Both the dominant effects of the two major genes were negative and nearly equally dominant to each other $\left(h_{\mathrm{a}}=-0.81 ; h_{\mathrm{b}}=\right.$ -0.80). The additive effects of the two major genes were lower than the dominant effects $\left(\left|d_{\mathrm{a}}\right|+\left|d_{\mathrm{b}}\right|\right.$ $\left.<\left|h_{\mathrm{a}}\right|+\left|h_{\mathrm{b}}\right|\right)$. Thus, the inheritance of stigma length mainly showed a negative dominant effect. The epistatic effect values of additive $\times$ additive $(i=-0.23)$ and dominance $\times$ dominance $(I=1.46)$ were negative and positive, respectively. The epistatic effect value of additive $\times$ dominant was negative with a stronger effect $\left.j_{\mathrm{ab}}=-0.41\right)$ and dominant $\mathrm{x}$ additive was positive with a weaker effect $j_{\mathrm{ba}}$ $=0.02$ ). The epistasis of the cumulative effect between the two major genes was negative. The heritability of the major genes in the $\mathrm{BC}_{1}, \mathrm{BC}_{2}$, and $\mathrm{F}_{2}$ generations were $44.39,43.95$, and $65.77 \%$, respectively. The heritability of polygenes in the $\mathrm{BC}_{1}, \mathrm{BC}_{2}$, and $\mathrm{F}_{2}$ varied from 14.65 to $39.32 \%$ (Table 7). The ratios of major gene heritability among the total heritability of the $\mathrm{BC}_{1}, \mathrm{BC}_{2}$, and $\mathrm{F}_{2}$ generations were $0.530,0.668$, and 0.818 , respectively. Therefore, positive major genes for stigma length were selected with high efficiency in the $F_{2}$ generation.

\section{DISCUSSION}

The mixed major gene plus polygene inheritance model is an important model in quantitative traits studies. The model was first proposed and executed in the inheritance analysis of human pedigrees (Elston and Stewart, 1973; Stewart and Elston, 1973). It was then expanded (Gai and Wang, 1998; Wang and Gai, 1998; Gai et al., 2000, 2003; Zhang and Gai, 2000; Zhang et al., 2003) and widely used for breeding of different traits in various plants (Chen et al., 2013; Irfan et al., 2014; Xia et al., 2014; Zhang et al., 2014). In order to obtain the larger floral organ traits from cabbage and to improve the flower size in broccoli, in this study, six populations, $\mathrm{P}_{1}, \mathrm{P}_{2}$, $\mathrm{F}_{1}, \mathrm{BC}_{1}, \mathrm{BC}_{2}$, and $\mathrm{F}_{2}$, obtained from broccoli and cabbage were used to measure the inheritance of the flower-size-related traits. Under the same greenhouse environment, the study could avoid the impact of environment; the segregation populations of $\mathrm{BC}_{1}, \mathrm{BC}_{2}$, and $\mathrm{F}_{2}$ used simultaneously, increased the accuracy of the results. As there were many flowers on each plant, we investigated 10-20 flowers (measured two to three times during the full-flowering period) for each plant, which could reduce the experimental error and increase the statistical power. However, this study was done in a single location and only $F_{2}$ hybrid was used. In future research, more years, more locations, and $\mathrm{F}_{2: 3}$ families would be used to increase the statistical power and to further clarify the inheritance of the flower-size-related traits. Further experiments with extensive research materials will deepen our understanding of the inheritance mechanism of floral organ size.

To date, few studies have been carried out on the inheritance of flower-size-related traits via the mixed major gene plus polygene inheritance model. Quantitative trait loci (QTL) analysis revealed that the floral organ sizes were controlled by polygenes. Bouck et al. (2007) found ten QTLs for nine floral traits in Louisiana irises; the QTLs had mixed effects with the effect sizes ranging from 8 to $69 \%$. Kelly and Mojica (2011) found that there were seventeen QTLs that controlled the size of corolla length and width, pistil length, anther length, and pistil length in Mimulus guttatus, 
and several kinds of interactions (sign epistasis, less-than-additive, synergism and effect masking) were routinely observed among the QTLs. Scoville et al. (2011) use QTL-mapping to parse the genetic variance of corolla width and pistil length of Mimulus guttatus. They identified nine loci and three QTLs with moderate effects explaining up to one-third of the genetic variance. However, the QTLs with the largest effect were relatively minor and were heritable. Furthermore, similar to other quantitative traits, epistatic interactions among the QTLs could sharply influence the variation in the floral traits (Frary et al., 2004; Kelly and Mojica, 2011). Galliot et al. (2006) suggested that the QTL with small to moderate effect controls the differences of flower size in Petunia, and that the flower sizes are most likely to be polygenic. However, the QTL with a major effect on the flower size variation have also been uncovered (Bouck et al., 2007; Scoville et al., 2011). The present study revealed that the corolla width, petal width, long stamen length, short stamen length, and anther length were controlled by polygenes; petal length and stigma length were both governed by two major genes and polygenes. Style length was controlled by one major gene and polygene; the heritability of the major gene varied from 10.35 to $40.60 \%$ and was lower than that of the polygene (41.85-68.44\%); thus, it was mainly controlled by polygenes. Our study revealed that the flowersize-related traits were mostly controlled by polygenes and different floral organ sizes with different heritability and gene interaction manners, which was consistent with the results of previous studies. The results presented in this study not only provide important genetic information for breeding, but also lays the foundation for QTL mapping of the flower-size traits.

\section{Conflicts of interest}

The authors declare no conflict of interest.

\section{ACKNOWLEDGMENTS}

We thank Professor Zhang Yuanming of Nanjing Agricultural University for providing the JSA software. Research supported by the China Agriculture Research System (Grant \#CARS-25-A), the National Natural Science Foundation of China (Grant \#31372067), the National High Technology Research and Development Program ("863" Program) of China (Grant \#2012AA100105), the Key Projects in the National Science and Technology Pillar Program of China (Grant \#2013BAD01B04), the Key Laboratory of Biology and Genetic Improvement of Horticultural Crops, Ministry of Agriculture, China, and the Science and Technology Innovation Program of the Chinese Academy of Agricultural Sciences (Grant \#CAAS-ASTIP-IVFCAAS).

\section{REFERENCES}

Akaike H (1977). On entropy maximum principles. In: Applications of Statistics (Krishnaiag G, eds.). North-Holland Publishing, Amsterdam, Netherlands, 27-41.

Bouck A, Wessler SR and Arnold ML (2007). QTL analysis of floral traits in Louisiana iris hybrids. Evolution 61: $2308-2319$. http://dx.doi.org/10.1111/j.1558-5646.2007.00214.x

Chen SL, Ma J, Wang TG and Zhang HS (2013). Genetic analysis of maize leaf spacing via mixed inheritance model of major genes plus polygenes. Afr. J. Agric. Res. 8: 5825-5831.

Conner JK and Sterling A (1995). Testing hyphotheses of functional relationships: a comparative survey of correlation patterns among floral traits in five insect-pollinated plants. Am. J. Bot. 82: 1399-1406. http://dx.doi.org/10.2307/2445866

Dudash MR, Hassler C, Stevens PM and Fenster CB (2011). Experimental floral and inflorescence trait manipulations affect pollinator preference and function in a hummingbird-pollinated plant. Am. J. Bot. 98: 275-282.http://dx.doi.org/10.3732/ ajb. 1000350 
Elston RC and Stewart J (1973). A análise de traços quantitativos para modelos genéticos simples de parental, F1 e dados retrocruzamento. Genetics 73: 695-711.

Fenster CB, Cheely G, Dudash MR and Reynolds RJ (2006). Nectar reward and advertisement in hummingbird-pollinated Silene virginica (Caryophyllaceae). Am. J. Bot. 93: 1800-1807. http://dx.doi.org/10.3732/ajb.93.12.1800

Finley JW (2003). The antioxidant responsive element (ARE) may explain the protective effects of cruciferous vegetables on cancer. Nutr. Rev. 61: 250-254. http://dx.doi.org/10.1301/nr.2003.jul.250-254

Frary A, Fritz LA and Tanksley SD (2004). A comparative study of the genetic bases of natural variation in tomato leaf, sepal, and petal morphology. Theor. Appl. Genet. 109: 523-533. http://dx.doi.org/10.1007/s00122-004-1669-x

Gai JY and Wang JK (1998). The backcross or $F_{(2: 3)}$ the family generations identification of quantitative trait gene-Mixed Genetic model. Zuo Wu Xue Bao 4: 402-409 (backcross data). Genetics 73: 695-711.

Gai JY, Zhang YM and Wang JK (2000). QT mixed inheritance model extended to two major genes + multigenerational joint analysis of multiple genes. Zuo Wu Xue Bao 26: 385-391.

Gai JY, Zhang YM and Wang JK (2003). Genetic System of Quantitative Traits in Plants. Science Press, Beijing, $120-126$.

Galliot C, Hoballah ME, Kuhlemeier C and Stuurman J (2006). Genetics of flower size and nectar volume in Petunia pollination syndromes. Planta 225: 203-212. http://dx.doi.org/10.1007/s00425-006-0342-9

Harder LD and Johnson SD (2009). Darwin's beautiful contrivances: evolutionary and functional evidence for floral adaptation. New Phytol. 183: 530-545. http://dx.doi.org/10.1111/j.1469-8137.2009.02914.x

Irfan M, Sun JX, Liu YB, Li X, et al. (2014). Genetic analysis of chlorophyll content in maize by mixed major and polygene models. Genetika 46: 1037-1046. http://dx.doi.org/10.2298/GENSR1403037I

Jeffery EH and Araya M (2009). Physiological effects of broccoli consumption. Phytochem. Rev. 8: 283-298. http://dx.doi. org/10.1007/s11101-008-9106-4

Johnson KL, Malladi A and NeSmith DS (2011). Differences in cell number facilitate fruit size variation in rabbiteye blueberry genotypes. J. Am. Soc. Hortic. Sci. 136: 10-15.

Kelly JK and Mojica JP (2011). Interactions among flower-size QTL of Mimulus guttatus are abundant but highly variable in nature. Genetics 189: 1461-1471. http://dx.doi.org/10.1534/genetics.111.132423

Kudoh $\mathrm{H}$ and Wigham DF (1998). The effect of petal size manipulation on pollinator/seed-predator mediated female reproductive success of Hibiscus moscheutos. Oecologia 117: 70-79. http://dx.doi.org/10.1007/s004420050633

Molina-Montenegro MA and Cavieres LA (2006). Effect of density and flower size on the reproductive success of Northoscordum graminum (Alliaceae). Gayana Bot. 63: 93-98. http://dx.doi.org/10.4067/S0717-66432006000100004

Nattero J, Cocucci AA and Medel R (2010). Pollinator-mediated selection in a specialized pollination system: matches and mismatches across populations. J. Evol. Biol. 23: 1957-1968. http://dx.doi.org/10.1111/j.1420-9101.2010.02060.x

Rodrigo J and Herrerro M (2002). Effects of pre-blossom temperatures on flower development and fruit set in apricot. Sci. Hortic. (Amsterdam) 92: 125-135. http://dx.doi.org/10.1016/S0304-4238(01)00289-8

Ruiz D and Egea J (2008). Analysis of the variability and correlations of floral biology factors affecting fruit set in apricot in a Mediterranean climate. Sci. Hortic. (Amsterdam) 115: 154-163. http://dx.doi.org/10.1016/j.scienta.2007.08.016

Scoville AG, Lee YW, Willis JH and Kelly JK (2011). Explaining the heritability of an ecologically significant trait in terms of individual quantitative trait loci. Biol. Lett. 7: 896-898. http://dx.doi.org/10.1098/rsbl.2011.0409

Shu JS, Liu YM, Fang ZY, Yang LM, et al. (2014). Study on the floral characteristics and structure in two types of male sterile lines of broccoli (Brassica oleracea var. italica). J. Plant Genet. Resour. 15: 113-119.

Shu JS, Liu YM, Li ZS, Zhang LL, et al. (2015). Effect of different pruning methods on flowering and fruiting characteristics between different types of male sterile lines in broccoli seed plants. Acta Hortic. Sin. 42: 689-696.

Stewart J and Elston RC (1973). Biometrical genetics with one or two loci: the inheritance of physiological characters in mice. Genetics 73: 675-693.

Thompson JD (2001). How do visitation patterns vary among pollinators in relation to ñoral display and ñoral design in a generalist pollination system? Oecologia 126: 386-394. http://dx.doi.org/10.1007/s004420000531

van Poppel G, Verhoeven DT, Verhagen H and Goldbohm RA (1999). Brassica vegetables and cancer prevention. Epidemiology and mechanisms. Adv. Exp. Med. Biol. 472: 159-168. http://dx.doi.org/10.1007/978-1-4757-3230-6 14

Walley PG, Carder J, Skipper E, Mathas E, et al. (2012). A new broccoli × broccoli immortal mapping population and framework genetic map: tools for breeders and complex trait analysis. Theor. Appl. Genet. 124: 467-484. http://dx.doi.org/10.1007/ $\underline{\text { s00122-011-1721-6 }}$

Wang JK and Gai JY (1998). Quantitative trait-mixed genetic $\mathrm{P}_{1}, \mathrm{P}_{2}, \mathrm{~F}_{1}, \mathrm{~F}_{2}$, and $\mathrm{F}_{(2: 3)}$ joint analysis method. Acta Agron. Sin. 24: 651-659.

Wetzstein HY, Yi W and Porter JA (2013). Flower position and size impact ovule number per flower, fruitset, and fruit size in pomegranate. J. Am. Soc. Hortic. Sci. 138: 159-166.

Xia Z, Zhang X, Liu YY, Jia ZF, et al. (2014). Major gene identification and Quantitative trait locus mapping for yield-related traits in upland cotton (Gossypium hirsutum L.). J. Integr. Agric. 13: 299-309. http://dx.doi.org/10.1016/S2095-3119(13)60508-0 
Young HJ and Stanton ML (1990). Inñuences of ñoral variation on pollen removal and seed production in wild radish. Ecology 71: 536-547. http://dx.doi.org/10.2307/1940307

Zhang J, Yao D, Ma J, Fu YP, et al. (2014). Genetic analysis of the major gene plus polygene model in soybean resistance to Leguminivora glycinivorella. Genet. Mol. Res. 13: 4983-4989. http://dx.doi.org/10.4238/2014.July.4.13

Zhang YM and Gai JY (2000). The IECM algorithm for estimation of component distribution parameters in segregating analysis of quantitative traits. Acta Agron. Sin. 26: 699-706.

Zhang YM, Gai JY and Yang YH (2003). The EIM algorithm in the joint segregation analysis of quantitative traits. Genet. Res. 81: 157-163. http://dx.doi.org/10.1017/S0016672303006141 